
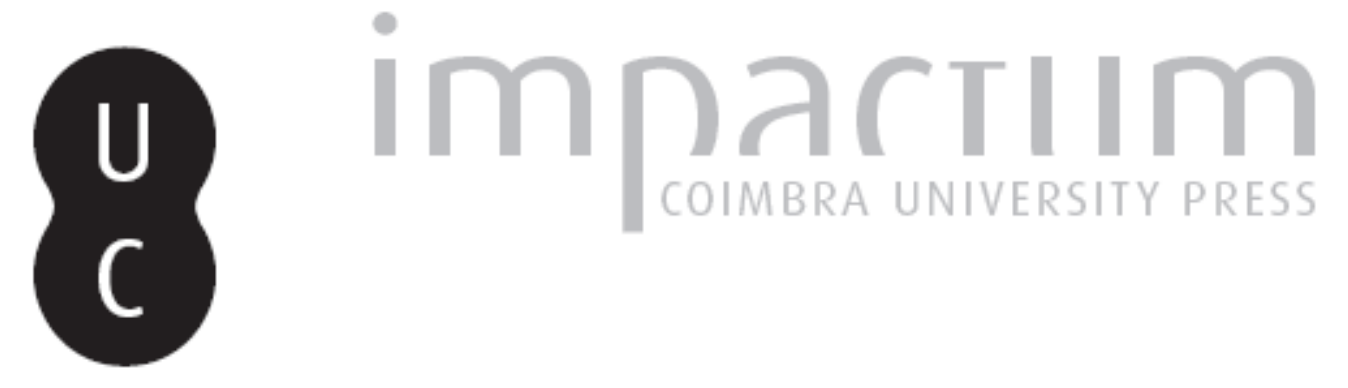

\title{
O brinquedo: a lancha do Calisto
}

\section{Autor(es): $\quad$ Moura, Armando Reis}

Publicado por: CIAS - Centro de Investigação em Antropologia e Saúde

URL persistente:

URI:http://hdl.handle.net/10316.2/41242

DOI:

DOI:http://dx.doi.org/10.14195/2182-7982_17_6

Accessed : $\quad$ 26-Apr-2023 14:06:00

A navegação consulta e descarregamento dos títulos inseridos nas Bibliotecas Digitais UC Digitalis, UC Pombalina e UC Impactum, pressupõem a aceitação plena e sem reservas dos Termos e Condições de Uso destas Bibliotecas Digitais, disponíveis em https://digitalis.uc.pt/pt-pt/termos.

Conforme exposto nos referidos Termos e Condições de Uso, o descarregamento de títulos de acesso restrito requer uma licença válida de autorização devendo o utilizador aceder ao(s) documento(s) a partir de um endereço de IP da instituição detentora da supramencionada licença.

Ao utilizador é apenas permitido o descarregamento para uso pessoal, pelo que o emprego do(s) título(s) descarregado(s) para outro fim, designadamente comercial, carece de autorização do respetivo autor ou editor da obra.

Na medida em que todas as obras da UC Digitalis se encontram protegidas pelo Código do Direito de Autor e Direitos Conexos e demais legislação aplicável, toda a cópia, parcial ou total, deste documento, nos casos em que é legalmente admitida, deverá conter ou fazer-se acompanhar por este aviso.

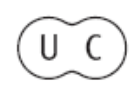




\section{Antropologia Portuguesa}

$16-17 \cdot 1999-2000$

Departamento de Antropologia | Universidade de Coimbra 


\title{
O Brinquedo - a lancha do Calisto
}

\author{
Armando Reis Moura \\ Urbanizaçāo Salvador Mendes, Lote 8 \\ Bias do Sul, 8700 Fuzeta, Portugal
}

\section{Resumo}

O brinquedo - a lancha do Calisto pode ser considerado como um bom exemplo de uma verdadeira miniatura, ilustrativa do tipo das lanchas de pesca da Costa do Sol (Maputo, Moçambique), pertencentes ao grupo tipológico das embarcações tradicionais de formas e técnicas de construção artesanal adquiridas por contactos de há muito tempo, havidos com pescadores portugueses e até de outras origens europeias, como por exemplo, a grega. Tais influências que se podem filiar em fenómenos de aculturação com outras marinharias, encontram-se na forma e modo de construção do casco e, no feitio e na maneira de armar a vela, que são características de origem nitjdamente portuguesas, e que se vāo perdendo ao longo do litoral para o Norte de Moçambique, onde prevalece exclusivamente a influência arábica.

Palavras-chave

Brinquedo, lancha, Costa do Sol, Maputo, Moçambique

\section{Abstract}

The toy - Calisto's sail boat may be considered a good example of a true miniature, ilustrative of the kind of fishing boat from the Costa do Sol (Maputo, Mozambique), which belong to the tipological group of traditional vessels, with artesanal shapes influenced by contact with Portuguese and others European fishermen. European influences is apparent in the shape and building process used for the hull and sail hanging, which is less in evidence further north where a strong Arabic influence asserts it self.

\section{Key words}

Toy, sail boat, Costa do Sol, Maputo, Mozambique 


\section{Ao modo de introdução}

O Calisto era um marinheiro, funcionário da Estação de Biologia Marítima (EBM), então chamada de Almirante Moreira Rato, na Ilha da Inhaca, Moçambique. Teria em 1968 uns trinta anos; era desempenado, sorridente e amável, delicado e atencioso. Filho de pescador e com artes de carpinteiro naval, morava entre o campo de aviação e o mangal do Farol, frente ao velho banco de coral da Sangala.

Um dia disse aos miúdos meus filhos, que estava a fazer-lhes um brinquedo. Isto já cerca dos anos 70; o Mando teria uns oito ou nove anos, o Gúgú apenas 5. De facto, alguns meses depois lá apareceu ele com um barquinho, de madeira de caixotes que davam à costa naquela parte da ilha e que era fértil em arrojados desse género e sempre muito procurados pela reutilização que permitiam.

$\mathrm{Vi}$, e achei o brinquedo engraçado, perfeitinho até, mas não dei mais importância, pois era sempre muito disputado pelos moços e seus companheiros de brincadeiras, o dia inteiro na areia da praia, ou na água do mar. Calculo os maus tratos que levou. Mas foi sempre sobrevivendo, chegando a ficar na ilha, quando vínhamos embora das férias ou fins de semana... alguém tomava sempre conta dele e o guardava até à próxima vez... as nossas estadias ali eram muito frequentes, de modo que na arrecadação da secretaria da EBM, lá estava sempre a lancha do Calisto...

Estava eu, então, muito longe de pensar, que na minha vida profissional, alguma vez deixaria a geologia, para me dedicar exclusivamente à biologia marítima, como aliás sempre fora meu gosto. $\mathrm{E}$ um dia - 23 de Agosto de 1973 - viria a ser o director daquela estação de biologia marítima! A minha vida havia, de facto, mudado, podendo dedicar-me a tempo inteiro ao que mais ambicionava, ao estudo do mar e de todos os mais variados assuntos a ele ligados, desde os seus produtos naturais, ouriços, estrelas do mar, até às conchas e a outras actividades a ele ligadas... A par disto, havia desenvolvido um grande interesse pelas embarcaçōes tradicionais, considerando-as como das mais notáveis produções do engenho humano. Daí que posteriormente tivesse recolhido numerosos elementos sobre os barcos que então animavam todo o litoral moçambicano, atraído tanto pelo seu número, como pela sua diversidade.

Foram passados mais de trinta anos... estando tudo isso já muito longe, no tempo e na distância. E eis que volta a surgir de novo a lancha 
do Calisto! Ao arrumar a cave, encontro o brinquedo, ainda com o casco impecável, mas o mastro, a verga e, sobretudo, a vela e demais cabos de manobra, num estado lastimoso, meio destruídos e até alterados pelas brincadeiras estouvadas dos moços, e naturalmente, pelas mudanças e sucessivas andanças da nossa vida, pelo que houve necessidade de os recuperar inteiramente, pelo que tive de the lançar um olhar mais detido.

Só então me apercebi da maneira como o brinquedo fora construído! O cuidado na forma, nas dimensões e proporçōes, o rigor do modo de envergar a vela e maneira de a marear. Fiquei deveras espantado e também contente, por voltar a poder olhar, com outros olhos, para a lancha do Calisto! Mais que um brinquedo, era uma miniatura. Talvez mesmo mais que uma miniatura, era um modelo!

\section{Descrição crítica do brinquedo - a lancha do Calisto}

Todo o brinquedo se encontra numa escala muita aproximada de 1:10 (figura 1). Pura coincidência? Ou foi intencionalmente escolhida? Hoje, revendo minuciosamente o brinquedo, admitimos como possível a utilização da escala decimal que seria de uso simples, rápido e directo. Tínhamos o conhecimento de que o Calisto estava a construir junto à sua habitação uma embarcação (figura 2). Transportar para a miniatura os seus elementos seria fácil se lesse em centímetros as dimensōes medidas em metros na lancha real.

\section{Ossatura}

A quilha é uma peça única, que recebeu à frente a roda da proa numa peça inteiriça, com o couce de vante, emenda e capelo, com um alefriz embutido. Não tem pois, nem coral, nem alfetana ou contra roda. Na porção posterior da quilha, também uma só peça representa o couce da ré e o cadaste, com a característica sambladura. Do mesmo modo, não apresenta o coral da popa, nem o contra cadaste ou alfetana da ré. Mas tal como para a proa, nota-se o alefriz do cadaste.

Uma curiosidade pode ser observada na proa do brinquedo. Não existe uma verdadeira roda da proa, mas antes o mesmo sistema utilizado no cadaste, só que aqui é menos oblíquo que além. E não é para facilitar a construção do brinquedo, pois nas embarcações reais isso também se verifica. 

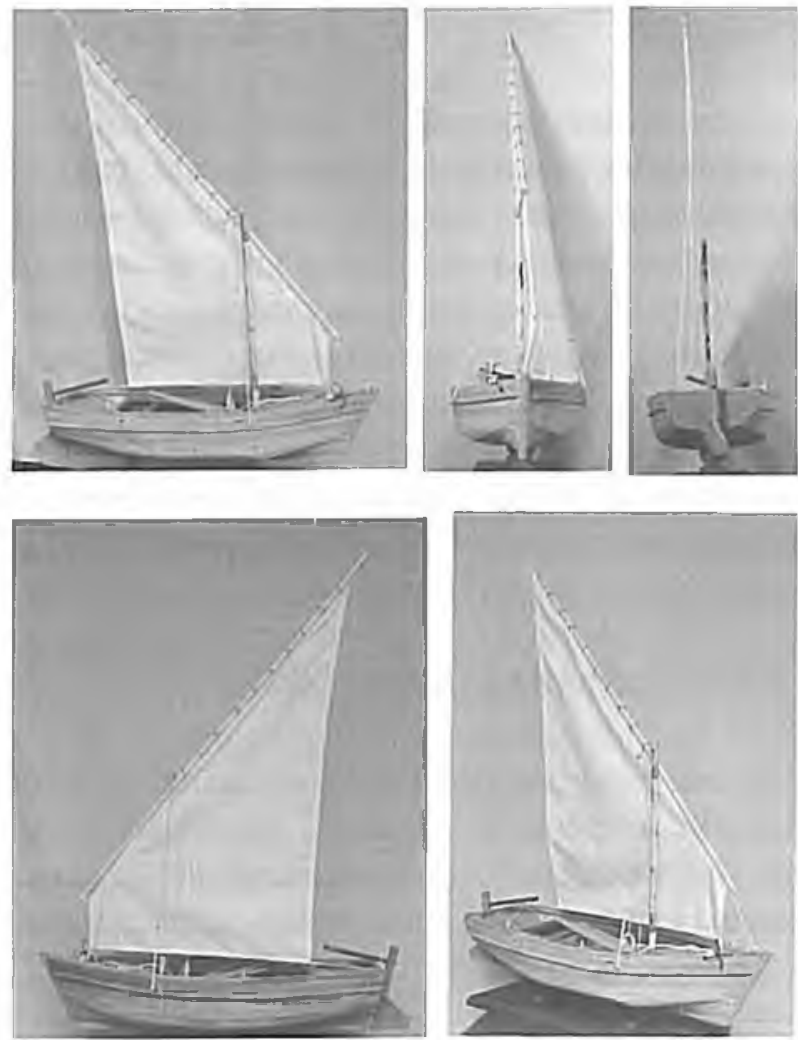

Figura 1. O brinquedo a "lancha do Calisto".

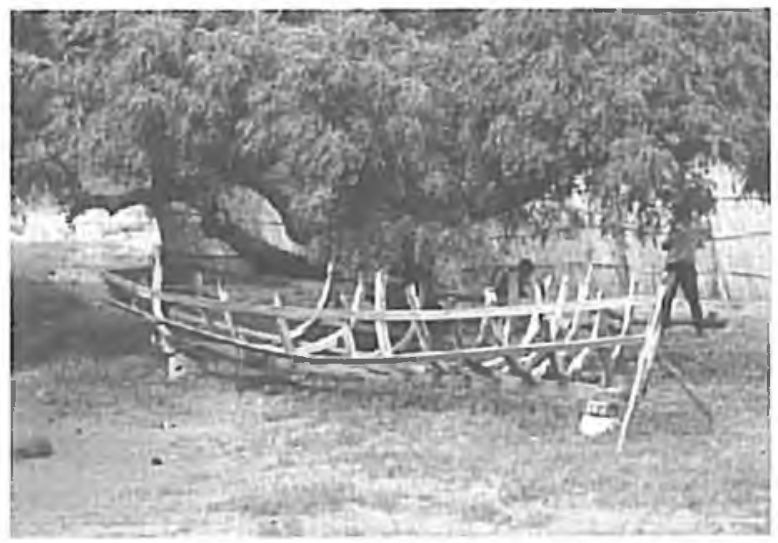

Figura 2. A lancha do Calisto em construçāo. 
As cavernas são continuadas pelos braços e cabeços. O seu pé entra nas hastilheiras e a sobrequilha fixa-se directamente sobre os pés das cavernas, que são cavilhados, conferindo grande resistência ao esqueleto. Passando pelo topo das balizas o alcatrate consolida o conjunto.

\section{Casco}

O tipo de construção do casco é de costado liso, em que as tábuas se dispōem em fiadas longitudinais, quando necessário emendadas topo a topo, ou com emendas um pouco oblíquas, ficando as juntas bem calafetadas.

Como a quilha não apresenta alefriz, não existem tábuas de resbordo, pelo que a primeira tábua do forro exterior encosta simplesmente à quilha. Também na zona de maior encolamento, as tábuas do fundo exterior passam às de obras mortas sem os costumados dentes. Interiormente não se encontram nem escoas, nem sarretas.

Rematando o forro exterior, na borda da falsa da amurada, apresenta uma falca com boeiros, burleiras ou mesmo escoas, para deixar sair as águas do convés. Como não existem cintas, nem tabica, logo abaixo da falca, corre o verdugo para protecção contra as coçaduras. Do lado de dentro da borda, um chapuz faz o forro interior, onde não se vê trincaniz, couceira ou cintura. Contudo houve a nítida intenção de não o encostar completamente ao convés para que as águas passem livremente.

Na parte interna do casco há apenas um dormente, onde assenta uma placa única de contraplacado simulando o tabuado do convés e ocupando toda a boca da embarcação. O casco é posteriormente fechado por um largo painel de popa, grande por causa da sua forma fugidia das alhetas poder ter grande aguagem. Curvas a preceito ligam a grinalda do painel ao alcatrate das bordas, onde junto ao seu ângulo interno têm um olhal com arganéu. Contudo falta a bussarda da proa.

O convés apresenta uma grande escotilha central ladeada de braçolas, mas não se percebe a existência da madre. Da braçola de vante até ao capelo há um forte reforço central, a tábua de reforço do convés, onde se vê um olhal para a amura.

Por baixo das braçolas laterais há três vaus, também com a função de bancos. No de vante, que quase encosta à braçola, o vau apresenta uma grande enora por onde passa o pé do mastro. Mais funcionais, há um central e outro mais à ré. Servirão para os remadores poderem manobrar com 
os remos, nas respectivas chumaceiras com toletes. Não estão a par, mas sim desencontradas, acreditando-se que a sua posição não será a mais correcta para o devido uso dos remos.

\section{Palamenta}

O leme, de robusta madre, mostra uma larga porta posteriormente alargada. A cana do leme, direita, insere-se na carlinga do cabeçalho, onde a sua mecha é presa com uma cavilha de ferro horizontal, quando o lógico seria de posição vertical. O leme liga-se ao cadaste por dois sistemas de machofêmea; no de cima, a madre do leme tem a agulha e no de baixo, o ollhal. No cadaste é ao contrário e em sentido oposto. As agulhas funcionam em sentidos opostos.

A âncora é do tipo fateixa, com quatro unhas. Há sempre a bordo uma pedra com um orifício central para ser usada como tal nos afloramentos de coral, para os ferros nāo ficarem presos, que pela sua forma e unhas são mais susceptíveis disso.

Os remos são em número de quatro, de longa pá de mais de um terço do seu comprimento. Funcionam nos toletes com estropos de cabo velho.

O mastro é de relativo grande diâmetro e pouco alto, pelo que é bem aplicável a terminologia marítima, de muita palha e pouca guinda. A mecha do pé tem a forma cónica e enfia numa carlinga adequada, escavada na sobrequilha. Não tem romã e no seu lugar abre um orifício transverso por onde passa a adriça da verga. Logo abaixo dele tem um reforço de apertadas voltas de cabo para defender da roçadura da verga. O perímetro diminui pouco da mecha ao calcês, que é redondo e obcónico.

A verga é de grande lais, comprimento quase duplo do mastro. No caso, o seu diâmetro diminui regularmente do carro ao lais superior. Ao terço tem também um reforço de apertadas voltas de cabo para protecção das roçaduras.

A vela apresenta um amplo painel de latino bastardo, com borda dobrada ou forrada, e devidamente entralhada. A testa é praticamente paralela à valuma e perpendicular à esteira que não tem saia. Aos punhos não apresenta reforços, nem tem rizaduras. $O$ gurutil tem envergues apenas ao longo de todo o carro. Na parte restante apresenta garrunchos com urracas próprias para correr ao longo da verga. 


\section{Cabos fixos}

Apresenta dois brandais, um para cada bordo. Podem ser simples e fixos ou de laborar, com caçoilos singelos retesados para o verdugo em olhais com arganel. A verga com a vela anda sempre por dentro dos brandais, à boa maneira portuguesa. Não apresenta estai.

\section{Cabos de laborar}

Adriça da verga (ostaga) iça pelo terço a verga através do buraco transversal abaixo do calcês. Na realidade ali não tem qualquer romã, nem gorne no lais superior do mastro, que facilite a manobra de a içar.

Do punho da pena da vela saem dois cabos: um, a adriça do punho da pena, que vai ao moitão do lais superior da verga e volta pelo cadernal do calcês do mastro a amarrar ao vau de vante; serve para içar a vela. $O$ outro cabo passa por dentro das primeiras urracas, sai livre ao outro gorne do cadernal e cai solto ou pouco preso; é a carregadeira para abafar o pano da vela na vante do mastro, à volta do carro da verga, o que é uma característica absolutamente local.

Do punho da amura sai um cabo, adriça da amura, que vai ao olhal a vante do mastro na tábua de reforço do convés e a amarrar à borda.

No punho da escota fixa-se a escota, que caça ou folga o painel da vela, passa pelo olhal do extremo da grinalda do painel da popa e, amarra na amurada.

No lais do carro, dois cabos, as orças, fixam-se a cada bordo, conforme a mareação do pano. Usam os dois juntos a amarrar no olhal do coral da proa.

\begin{tabular}{|llc|}
\hline \multicolumn{2}{|c|}{ Dimensões do brinquedo } \\
Comprimento & 54,5 & \\
Boca & $\mathrm{cm}$ \\
Pontal & 21,0 & \\
Comprimento do mastro & 10,5 & \\
Comprimento da verga & 36,5 & \\
Área vélica & 69,5 & \\
Comprimento do remo & 1850 & $\mathrm{~cm}^{2}$ \\
& 26 & $\mathrm{~cm}$ \\
\hline
\end{tabular}


É assim o brinquedo - lancha do Calisto que, como vạmos ver, representa muito bem o tipo de embarcação regional utilizada na Baía do Maputo e nas embocaduras dos vários rios que ali vão desaguar. Para o mar aberto, exterior à baía, não se verifica qualquer navegação com embarcações tradicionais. Em primeiro lugar porque as condições oceanográficas o não permitem. Em segundo lugar, porque as zonas abrigadas mais próximas se situam a mais de $50 \mathrm{~km}$ para Sul da Ilha da Inhaca e o porto mais próximo e para Norte, a barra do Limpopo e o Xai-Xai, a mais de 100 !

\section{A Baía do Maputo}

A ampla baía do Maputo tem a forma geral de um losango, com cerca de 50 por $30 \mathrm{Km}$ nas suas diagonais, respectivamente, Norte-Sul e OesteEste. É no seu vértice mais ocidental que se situa a capital, cidade do Maputo, do lado norte e com a Catembe a Sul, separadas pelo estuário conjunto dos Rios Umbelúzi e Tembe.

No extremo Sul desagua o Rio Maputo, enquanto que no vértice mais a norte, lança-se na baía, o Incomáti, com as três Ilhas Xefinas na foz, e acompanhado pela longa língua de areia, que dá pelo nome de Ponta da Macaneta. Pelo lado Sudoeste, a ligação ao mar aberto é fechada pela extensa ponta continental do Machangulo, e pelas Ilhas da Inhaca e dos Portugueses, separadas da terra firme pela Golada de Santa Maria.

Apenas pelo nordeste, entre a Ilha Xefina Grande e as Ilhas da Inhaca e Portugueses, se faz a conexão com o mar largo. É, pois, uma vasta baía de mais de $750 \mathrm{~km}^{2}$ ! À sua periferia encontramos grande população que se dedica à actividade piscatória tradicional e apanha de marisco, como a Aldeia dos Pescadores, Catembe, Machangulo e Inhaca. Utiliza nas suas deslocações e faina de pesca, embarcações construídas artesanalmente, com grande esforço, muita dedicação e, sobretudo, grande engenho, a que nāo podemos ser, nem ficar indiferentes. 


\section{Descrição do tipo da lancha da Costa do Sol}

...os seus barcos, assim como a arte de marear; ganharam um jeito nitidamente europen

(in Vieira, 1954: 6)

Em toda a área da Baía são utilizadas pequenas e características embarcações (figura 3 e 4 ), deslocando de 2 a 4 toneladas, construídas no próprio local por carpinteiros e pescadores, segundo técnicas já tradicionais. Isso teria sido fruto de inúmeros contactos com pescadores e artistas navais portugueses, e até gregos, ali antigamente radicados durante muito tempo.

Estas lanchas, um tanto cheias de formas, possuem um agudo talhamar, com a roda da proa um tanto pronunciada e um pouco oblíqua. Como já antes assinalámos, a proa apresenta uma singular forma de construção. A roda da proa é rectilínea e insere-se na quilha, do mesmo modo que o cadaste. Dele difere pela sua maior obliquidade. Assim o cadaste, é quase vertical, com um largo painel da popa, devido às suas alhetas fugidias.

O costado liso é formado por tábuas encostadas e por vezes emendadas topo a topo "em bisel", bem pregadas às grosseiras balizas. Estas são formadas por cavernas, braços e aposturas emendadas. As tábuas do costado têm todas as juntas bem calafetadas com cordame usado e alcatroadas a preceito.

É muito raro verem-se estas embarcações de boca aberta, mas quase sempre, de convés corrido, com pequena borda falsa, sendo a sua parte central unicamente ocupada pela boca de uma única escotilha, para uso do pessoal e da carga, possuindo braçolas e contrabraçolas pouco salientes. A meio da escotilha leval um vau, que serve também de bancada transversal e outro a meio do vão posterior; para vante, ainda outro vau, quase sempre com a enora por onde passa o pé do mastro.

Nesse vau de vante, a enora pode ser substituída apenas por um meio círculo escavado e fechado com um galindréu ajustado ao corpo do mastro. Este é de pouca guinda, calçando a mecha do pé numa curiosa carlinga aberta na sobrequilha. No caso presente apenas uma cavidade cónica, onde o pé do mastro, talhado a preceito se encaixa perfeitamente.

O mastro é sempre inteiriço e mocho, envergando uma ampla vela latina; é aguentado lateralmente por apenas um, ou dois pares de brandais, 

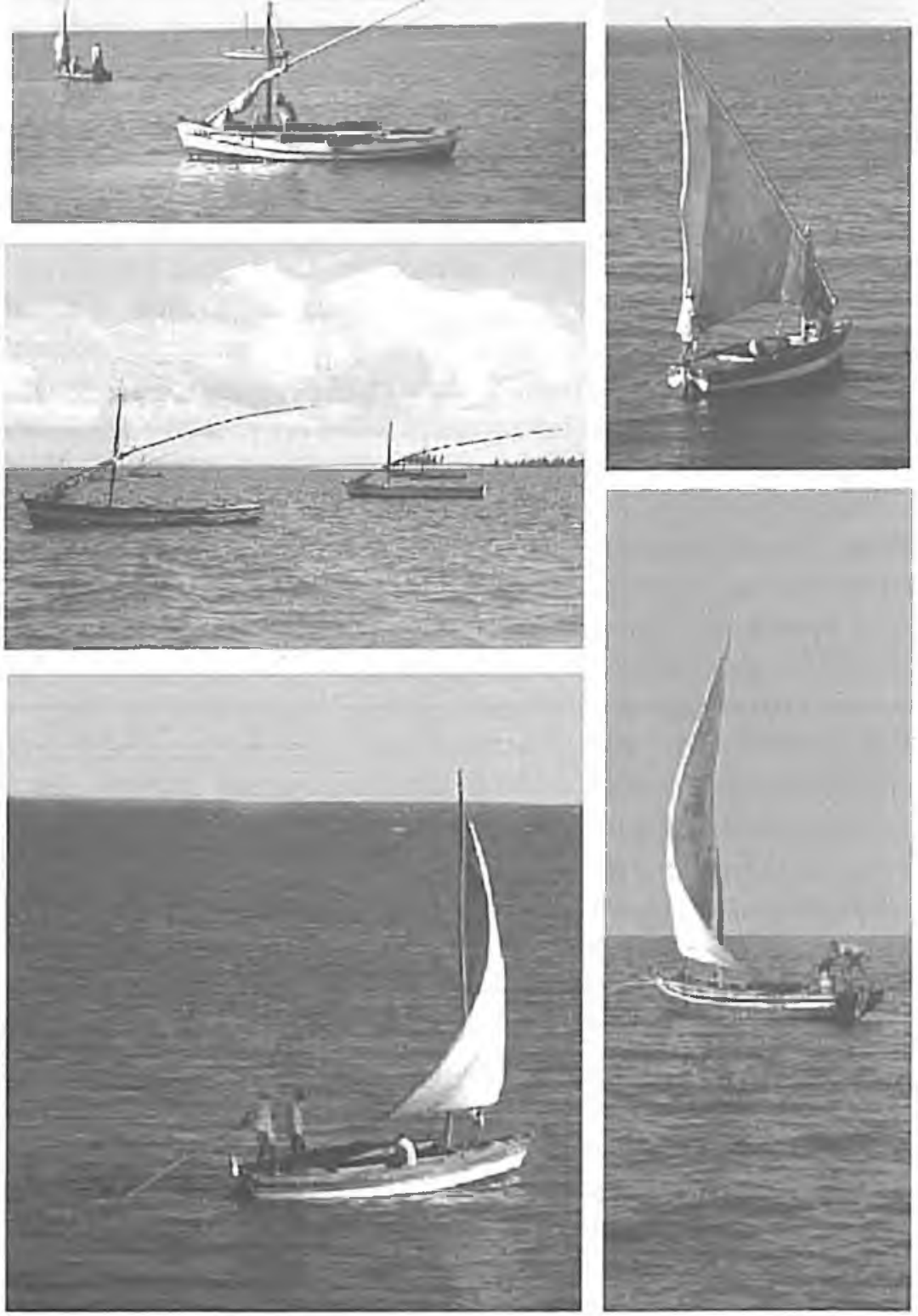

Figura 3. Lanchas da Costa do Sol. 


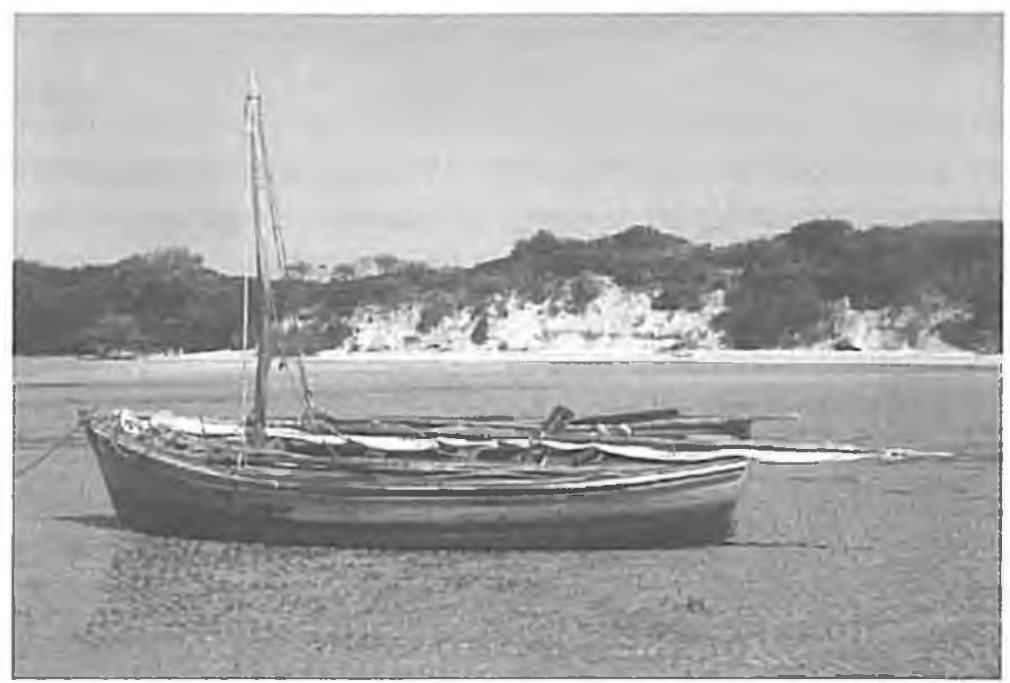

Figura 4. Uma lancha idêntica à do Calisto, na Ponta Rasa, Ilha da Inhaca.

a cada borda e em geral por um estai. Os brandais podem ser simples e só ligados a um arganéu ou mais sofisticadamente tensos com macacos esticadores. $\mathrm{O}$ uso de bigotas com colhedor, mesmo de confecção singela, raramente foi visto.

A verga, muitas vezes apenas uma única e magnífica vara de bambú, tem cerca de três vezes o comprimento do mastro, anda sempre por vante deste, nunca se vendo com emenda e penol. Muito raramente aparece uma verga de madeira e quando isso acontece, tem um teque ao seu carro.

A vela envergada pode ser do tipo exclusivamente de latino triangular com largo painel; a maior parte das vezes usam-na bastarda, com uma pequena testá, que é paralela à valuma e nāo oblíqua como nas algarvias, a amarrar curto num arganéu fixo ao meio do convés de vante, a meia distância entre o beque e o mastro. O olhal de fixação é geralmente uma grossa tábua central do convés.

Pode não haver estai e entāo, uma curta orça amarra o carro da verga ao arganéu da parte posterior do beque; podem mesmo ser duas para um e outro bordo, conforme a mareação. Por vezes, o estai deixa o beque $\mathrm{e}$ fixa-se ao lais inferior da verga, aguentando o carro como se de um teque se tratasse. 
A vela é envergada de um modo muito curioso e único em Moçambique: Só o terço inferior do gurutil, isto é, a sua porção que fica para vante do mastro, correspondente ao carro da verga, é que apresenta envergues; a parte superior restante possui 4,5 ou mais garrunchos com urracas que vão correr ao longo da verga, içados por meio de uma adriça; esta chega ao lais superior da verga, gornindo num pequeno moitão para essa finalidade e passando depois por um dos gornes do cadernal do calcês e amarra no vau, ou mesmo na borda.

Curiosamente, e também ligado ao punho da pena, existe uma carregadeira, que passa por dentro das primeiras urracas, para poder carregar rapidamente o pano; este fica todo amarfanhado junto ao carro, quando o barco está ancorado ou é preciso subtrair rapidamente a vela à acção do vento.

A vela não tem rizaduras nem forras de reforço aos punhos. Também não verificámos a existência de saia. Contrastando com o talhe das velas do Norte do País, em que a valuma e a esteira são praticamente iguais, aqui o latino segue as proporçōes de 3:4:5, respectivamente para a esteira, valuma e gurutil, o que lembra muito o distante e antigo Portugal.

A lancha pode navegar não só à vela, como também a remos, podendo armar dois a cada borda. Para isso há quatro toletes em outras tantas chumaceiras colocadas a preceito no alcatrate da embarcação. A tripulação normal é de 3 homens, ou mesmo de cinco, podendo ir mais para a faina da pesca, sobretudo se for de arrasto para terra, mas apenas um chega para governar a embarcação e navegar à vela. Isso acontece nos percursos mais longos.

O leme é o vulgar, de porta larga e cana do leme direita, de emechar no cabeçalho da madre do leme, ou de encaixar. Neste caso, a cana do leme tem uma curvatura apropriada, que permita virar de um lado para o outro, sem bater na grinalda do painel da popa. A cachola precisa também de ter uma mecha (espiga), onde encaixa a clara da cana do leme. Isto é mais raro por ser difícil de encontrar madeira a preceito.

A âncora vai desde o tipo de pedra servindo de poita, à fateixa e à do tipo do almirantado, mais rara por ser de compra. A natureza dos fundos regula a utilização dos dois primeiros tipos, como tivemos oportunidade de verificar. 


\section{Ao modo de conclusão}

À primeira vista o brinquedo-lancha lembra singularmente as antigas lanchas de serviço às armações de pesca do atum algarvias, de há quatro ou cinco décadas atrás. Mas um olhar mais detido permite assinalar diferenças importantes, que tentámos mostrar ao longo da descrição crítica.

É fora de qualquer dúvida, contudo, representativa do tipo de lanchas da Costa do Sol, antes chamada da Baía de Lourenço Marques e, portanto, uma embarcação tradicional de formas e técnicas de construção adquiridas, de acordo com a nossa própria tipologia (Moura, 1972). Fundamentam-se essas diferenças em características como a da forma do casco, o seu tipo e modo de construção e, o feitio e modo de armar a vela.

Quaisquer dessas características, como que se perdem e desvanecem ao mesmo tempo que outras diferentes crescem e aumentam em latitude, para o Norte de Moçambique e além, onde prevalece uma nítida e exclusiva influência arábica e mesmo indiana. A terceira influência de povos e marinharia estranha à região e que ali se faz sentir, é a de cariz indonésico e apenas afecta as embarcaçōes mais ligeiras, que referimos como pertencentes ao conjunto de embarcações de formas e técnicas de construção próprias, ou se se preferir, locais.

\section{Agradecimentos}

Agradecemos ao Senhor António dos Santos do Carmo, construtor naval, que ainda mantém em actividade os estaleiros da Fuzeta, a enorme paciência que teve em rever comigo, no aspecto da técrica da construção naval, o brinquedo - a lancha do Calisto e pelos generosos esclarecimentos especializados prestados.

\section{Bibliografia}

Moura, A. R. 1972. Barcos do Litoral de Mofambique. Monumenta, Boletim da Comissão dos Monumentos Nacionais de Moçambique, $n .{ }^{\circ} 8$.

Vieira, A. C. 1954. Embarcaçōes Indigenas da Costa de Moçambique. Lourenço Marques, Cadernos 